\title{
FRIGHTENING OR ENLIGHTENING? AN APPRAISAL OF THE FUNCTIONS OF THE MILITARY METAPHOR IN THE AIDS CONTEXT
}

\author{
Theresa Biberauer \\ Department of General Linguistics \\ University of Stellenbosch
}

\section{INTRODUCTION}

Acquired Immune Deficiency Syndrome - or AIDS as it is more commonly known - was first identified in 1981. By the mid-80s, people were starting to realise that AIDS was not just going to run its course and "go away" as other epidemics had in the past. At this time, medical professionals were also starting to realise that the virus causing AIDS - the so-called Human Immunodeficiency Virus or HIV - was a complex entity, one which they would not easily come to understand. In this climate of fear and uncertainty, it is not surprising that people began trying to make sense of the new, threatening disease by likening it to other more familiar experiences and entities. Thus a number of conceptual AIDS metaphors arose, many of which still to a greater or lesser extent survive today.

In an article on the subject of the so-called language of AIDS, Ross (1988) suggests that it is possible to identify a number of conventional AIDS metaphors. Among these, she mentions the PUNISHMENT ${ }^{1}$ metaphor, the CRIME AND CRIMINAL metaphor and the MILITARY metaphor. In terms of the PUNISHMENT metaphor, AIDS should be seen as a just desert for some kind of unacceptable (illegal? immoral? hedonistic?) action or behaviour. In terms of the CRIME AND CRIMINAL metaphor, HIV is viewed as a master criminal, a kind of "pathological personality" (Ross 1988: 43) which strikes without any regard for the age, sexual orientation or status of its victims. As the master criminal, HIV is also always one step ahead of the researchers who are involved in the race to "unravel[ ] the secrets of the shifty AIDS virus" (Ross 1988; 43). Clearly, neither of these metaphors is very useful in helping us to understand AIDS or to care for those unfortunate enough to have contracted it: the PUNISHMENT metaphor merely promotes insensitivity towards AIDS patients ${ }^{2}$ and their lot, while the CRIME AND CRIMINAL metaphor suggests that AIDS patients themselves are only of secondary interest to the vinus itself. This latter metaphor furthermore portrays HIV as such a cunning operator that it seems to suggest that one might as well give up on life once one has been diagnosed as HIV positive. In the light of metaphors such as the PUNISHMENT and 
CRIME AND CRIMINAL metaphors, then, it could indeed seem tempting to declare - as Susan Sontag (1977: 3) did - that:

. the most truthful way of regarding illness - and the healthiest way of being ill - is the one. most purified of, most resistant to, metaphoric thinking ...

$\because$, Metaphors hove to be exposed, criticized, belabored (sic), used up.

Insofar as her statement relates to metaphors of the PUNISHMENT and CRIME AND CRIMINAL type, there can surely be little objection to what Sontag has to say. As a former cancer patient herself, she must know only too well how personally demoralizing and socially stigmatizing such metaphors can be. I do not, however, believe that all metaphors employed within medical contexts generally and the AIDS context specifically should be summarily dismissed as "inaccurate, misleading and nefarious" (Sontag 1977: 5). As Sontag herself concedes in AIDS and its metaphors (1988: 94):

Injot all metaphors applied to illnesses and their treatment are equally unsavoury and distorting.

In this paper, I wish to examine the validity of Sontag (1977 and 1988) and Ross's (1988 and 1989) view that the MILITARY metaphor should number among those metaphors that should be denigrated as "unsavoury and distorting". Their principle reasons for advocating this standpoint are:

(a) that the MILITARY metaphor "draws one to accepting otherwise unacceptable ideas" (Ross 1988: 45), e.g. that not only HIV but also the carrier is the enemy; and

(b) that the MILITARY metaphor has the potential to "overmobilize[], ... overdescribe[], and ... contribute[] to the excommunicating and stigmatizing of the ill" (Sontag 1988: 94).

At this point, I would like to make it clear that I am going to discuss the use of the MILITARY metaphor within the context of interaction between doctors, nurses, counsellors and other healthcare workers on the one hand, and AIDS patients and their families on the other. This rather lengthy context description will henceforth be designated the AIDS context. Note that in my discussion of the use of the MILITARY metaphor within the AIDS context, I will at no point be referring to the use of this metaphor within any public sphere. Naturally, the MILITARY metaphor is frequently used - and sometimes, particularly by the sensational media, abused - within this sphere. As far as the use of the MILITARY metaphor within 
these contexts is concerned, I am inclined to go along with Ross (1989) when she says that ovenuse of this metaphor by the media and those controlling public policy may lead legislators, researchers and even general practitioners to lose sight of compassion as they race to beat the enemy rather than soothe the sick. As fat as the use of the MILITARY metaphor within the AIDS context is concemed, however, I believe that one should be very cautious before summarily dismissing the merits of this metaphor. As I will show, the MILITARY metaphor fulfils a number of important functions within the AIDS context and, as such, contributes towards enlightening the frightening subject of AIDS.

\section{A BRIEF BACKGROUND TO THE THEORY OF METAPHOR UNDERLYING MY DISCUSSION OF THE MILITARY METAPHOR.}

According to Lakoff and Johnson (1980) whose model I am using to analyse the MILITARY metaphor, metaphor is a great deal more than just a linguistic phenomenon or stylistic device involving a deviation from normal usage. This is the impression one might get from the way metaphor is dealt with at school-level and even in literature classes at university-level. For Lakoff and Johnson, however, metaphor is a primarily conceptual issue, i.e. Lakoff and Johnson believe that the use of metaphoric utterances by a speaker reflects a metaphoric understanding on his part of the concept(s) in question. Thus, if someone says I am going to fight this disease ( = AIDS) all the way; it is going to have to work very hard to beat me!, Lakoff and Johnson would say that this metaphoric mode of expression reflects a metaphoric understanding of AIDS in terms of which:

(a) the disease is seen as an opponent or enemy;

(b) the disease process is seen as a war; and

(c) the appropriate response by the patient is taken to be the offering of determined resistance.

Naturally, if metaphor is regarded as a conceptual phenomenon, the use of metaphoric utterances has particular implications that the use of such utterances would not have were metaphoric utterances regarded as purely linguistic devices. It is clear from Sontag and Ross's objections - recall they object that the MILITARY metaphor can affect one's judgements about and response to AIDS patients - that they, like Lakoff and Johnson, believe that metaphors are conceptual phenomena capable of influencing our thought and action. 
133

\section{THE FUNCTIONS OF THE MUIITARY METAPHOR}

Essentially, conceptual metaphors such as the MILITARY metaphor can be sajd to fulfil one or more of the following four functions:

(a) a structuring function. If we think in terms of the conceptual metaphor MEDICINE IS WAR ${ }^{3}$, one of the sub-metaphors entailed by the MILITARY metaphor, we can, for example, structure the (to the layman) less familiar concept of 'medicine' in terms of the more familiar concept of 'war': we can see the disease as an enemy; the doctor as a military general; medicine, therapy and other treatment as weaponry; and, somewhat unsatisfactorily, the patient as a victim.

(b) an illuminatory function. In showing how the unfamiliar is sinnilar to the familiar, conceptual metaphors play an important illuminatory role. For laypeople, this is a particularly useful aspect of metaphor since it enables them to understand new concepts on the basis of old ones.

(c) a compensatory function. People often find themselves in situations where they do not know the "correct" terminology to express their ideas. This understandably happens frequently in highly specialized domains such as the medical one. In such situations, conventional conceptual metaphors can provide speakers with alternative means of representing that which they would not otherwise confidently be able to express. A young AlDS patient who refers to the immune cells as body soldiers is, for example, making use of this compensatory, impromptu vocabulary extension mechanism.

(d) a manipulative function. By focusing attention on particular similarities between two domains which are actually unrelated, conceptual metaphors are necessarily prone to what Lakoff and Johnson (1981: 292) describe as the highlighting and hiding dilernma: in highlighting certain aspects of a concept, a conceptual metaphor simultaneously hides others which are not coherent with that metaphor. As such, conceptual metaphors obviously constitute an extremely effective manipulative device. It is this function of the MILJTARY metaphor that Sontag and Ross are most concerned about.

Let us now look in more detail at the functions fulfilled by the MILITARY metaphor within the AIDS context. 


\subsection{The structuring function}

Because AIDS is in many ways such a complex disease, - one, in fact, which researchers have not fully fathomed even after nearly fifteen years of research - the structuring function fulfilled by the MILITARY metaphor is of particular importance within the AIDS context.

Some of the most salient parallels drawn between the concepts of 'AIDS' and 'war' are the following:

\section{(a) AIIDS/HIV IS TRE ENEMY}

In view of the fact that AIDS is such a relentlessly debilitating disease, it is understandable that people should view AIDS and/or HIV as an enemy which is making violent assaults on the body. Thus AIDS patients and their families may speak of having to fight each new onslaught of the AlDS virus; or counsellors may advise AIDS patients to use condoms as a barrier or first defence against the disease/virus; Similarly, on the basis of the IMMUNE SYSTEM IS A DEFENCE SYSTEM metaphor, - a sub-metaphor within the MEDICINE IS WAR complex - doctors may describe HIV as an invader who opens the gates of the immune system, allowing all kinds of opportunistic infections to attack the body. Children may also be told to view their bodies' immune cells as soldiers which do battle with the HTVirus.

\section{(b) THE DOCTOR IS THE COMMANDER OF THE DEFENDING SIDE}

By virtue of the fact that doctors have superior knowledge and experience within the AIDS (or any other medical) context, it is tempting to draw a parallel between doctors and/or counsellors and military commanders. Instances of this metaphor are our references to doctors' prescriptions as doctors' orders and the way doctors frequently refer to their healing regimen as a plan of action or, more colloquially, a $P$. of $A$.

\section{(c) THE PATIENT IS THE VICTIM}

Because AIDS sows death and destruction, it is understandable that people should want to refer to the (innocent) $)^{4}$ victims of AIDS. This is a somewhat unfortunate parallel since many AIDS patients do not appreciate this label at all. Particularly, those belonging to the suppor group, Body Positive ${ }^{5}$, utterly reject the PATIENT IS THE VICTIM sub-metaphor of the MILITARY metaphor. They prefer to see themselves as people living with AIDS or, under certain circumstances, AIDS patients. The 
PATIENT IS THE VICTIM is thus one sub-metaphor of the MILITARY metaphor which should be used with sensitivity.

(d) MEDICAL TECHNOLOGY IS THE WEAPONRY and A POSITIVE OUTLOOK IS THE WEAPONRY

To a limited extent, doctors may refer to AZT and other medications and therapies as the armamentarium with which they are fighting AIDS. Because there is still no effective "weapon" - no so-called magic bullet - to combat AIDS at this stage, these references are generally limited, however. In my research, a far more common metaphor was the A POSITIVE OUTLOOK IS THE WEAPONRY metaphor. Counsellors in particular employed this metaphor in advising their clients to stay positive in order to keep that virus in check. Because it suggests that they themselves can take action, this metaphor is particularly useful as a motivational mechanism within the AIDS context. According to psychoneuroimmunologists, it also has psychological validity since patients who maintain a positive outlook do indeed seem to stay healthy for longer (Jemmot 1985 and Kiecolt-Glaser and Glaser 1992).

\subsection{The illuminatory function}

The MILITARY metaphor provides laypeople within the AIDS context with a means to talk about the complex disease that is AIDS.

Morely (cited in Màseide 1989: 156) and Bliesener and Siegrist (1989; 182) point out that:

few patients are so well informed that they fully comprehend the structure, function and general physiological effects of ... pathogenic organisms

Within the AIDS context, many patients have little if any education and many others are children. Explaining the complex disease that is AIDS to these patients in a readily comprehensible way could thus be potentially problematic. How, for example, would one refer to the multitude of infinitesimal inmune cells, each of which specialists denote by means of a seemingly arbitrary conglomeration of alphabetic characters and numerals? ${ }^{6}$ How would one explain what a virus is when it belongs to a category of pathogens whose workings and structure even the most learned scientists cannot fully fathom? Obviously, with so many children and (semi-) illiterate patients, one cannot talk about phagocytes and macrophages which can no longer ingest pathogens. If a healthcare worker or family member, bowever, refers to body-soldiers which are sick, being unable to fight off bad germs that attack their 
bodjes, they may understand. The MILTTARY metaphor therefore provides a mechanism via which patients of all ages and backgrounds can understand - at least in some elementary way the complex workings of the immune system.

\subsection{The compensatory function}

AIDS patients who have had their illness explained in terms to which they can readily relate (see 3.2 above) have been put in a position where they can speak about their illness themselves. Being able to do this is extremely important: as Reich (1989: 94) says, "[t]he one who can name has power over what is named". The counsellors whom I interviewed all agreed that AIDS patients who could understand their ilness and how it worked were more likely to raise issues that were worrying them than those who merely understood that they had an incurable disease. It seems to be the case that patients who have heard their caretakers using simple metaphoric images like body-soldiers and processes of attack and counter-attack decide that such terminology is "acceptable" and consequently do not hesitate to use it themselves.

\subsection{The manipulative function}

If one were to judge on the basis of the existing literature, one would have to believe that the function most commonly performed by the MILITARY metaphor is that of manipulation. Recall, for example, the accusation made by Ross (1988: 45) that the MILITARY metaphor can lure one into accepting otherwise unacceptable ideas. She also asserts (1989: 55) that the MILITARY metaphor can set up an illusory hope for an ultimate recovery following the defeat of the HIV army. Sontag (1988: 11), too, calls for the "using up" of the MILITARY metaphor on the grounds that it inevitably leads from the "demonization of the illness [which is bad enoughl to the attribution of fault to the patient". Let us look critically at some of their and other writers' - specific accusations.

Accusation 1 : the MILIT ARY metaphor encourages doctors to be unnecessarily aggressive (Hodgkin 1985: 1821) so that they overprescribe drugs and generally go "all out" chasing after a victory which is unattainable.

As far as I could ascertain on the basis of my interviews, it would seem as if healthcare workers and AIDS patients alike are very much aware of the fact that AIDS in the final analysis is not something that can be "solved" in the same way that wars are. For one, doctors are extremely conscious of the fact that current treatments are at best palliative. In the light of this awareness, overly aggressive treatment clearly is neither reasonable nor 
economically or psychologically sound. Furthermore, physicians are also very much aware of the fact that overly aggressive therapy can actually weaken the already compromised immune system, causing it to capitulate to the HIV virus earlier than it might otherwise have done. The fact that aggressive action is called for by the MILITARY metaphor is thus irrelevant here: doctors will not blindly act in accordance with a conceptual metaphor (even a pwerful one such as the MILITARY metaphor) if their experience of the situation tells them that the metaphor does not entirely "fit" that situation.

Accusation I therefore does not seem to hold water. It is my suspicion that this objection originated during the early AIDS years when panic prevailed and doctors, lacking the insight we have today, blindly hoped that aggressive therapy would kill the causative agent.

Accusation II : the MILITARY metaphor presents death as an undesirable outcome, thereby denying people the benefits of an acquiescent approach to death and simultaneously driving doctors to strive for an "impossible immortality" for their patients (Lapierre 1991: 83).

For patently obvious reasons, death within the war context (particularly of those on our side) is viewed as an undesirable outcome. This view is also reflected in the MILITARY metaphor - consider the way people talk about resisting and fighting or even cheating and outwitting death. Within the AIDS context, however, it is undeniably true that death could in many cases appropriately be viewed as a friend by patients wracked by the debilitating onslaughts of AIDS. Does the MILITARY metaphor then not deprive these people of a peaceful end by suggesting that they should fight to the end? The answer to this question is no. Suggesting that metaphors - even powerful conceptual metaphors such as the MILITARY metaphor - are solely responsible for someone's actions or attioudes reveals a culpable misunderstanding of the role of conceptual metaphor within our lives. To be sure, conceptual metaphors enable us to understand the world by structuring it for us, but they are not the sole deterninants of our world-view. As Holland (1982: 295) points out, metaphor is not the only conceptual tool we have at our disposal to make sense of our experiences: key events in our past experience, for example, play an important role as do key words associated with particular situations (e.g. compassion within the hospital scenario). When a patient wants to fight to the end, this is likely to be the result of a whole complex of factors - his past experiences and his individual temperament among a host of others, for example. The DEATH IS AN ENEMY submetaphor can thus at most be regarded as one of several contributory factors which lead to a resisting approach to death. 
Accusation III : The MILITARY metaphor reinforces the autocratic stereotype of the doctor, thereby increasing an already considerable power differentia] between physician and patient (Hodgkin 1985: 1821).

If doctors only saw their role in terms of a single metaphor, Accusation III would have greater validity than it does. It is, however, a fact that complex concepts are not structured in terms of a single metaphor only. Thus many doctors understand their role in terms of a variety of metaphors and other conceptual tools, the situation determining which metaphor is most appropriate. In situations where the patient's input is required to secure the success of the treatment, for example, an autocratic approach such as that suggested by the THE DOCTOR IS A MILITARY COMMANDING OFFICER metaphor is clearly inappropriate. Under this circumstance, the doctor may rather see his role in terms of a THE DOCTOR IS A PARTNER IN A COLLABORATIVE ENTERPRISE metaphor. he may then speak of the two of us trying to figure this out rather than of doctors' orders or I prescribe. Once again, it therefore seems as if Accusation III is not entirely well-founded.

Accusation IV : The MILITARY metaphor does not provide for a role for patients except possibly for the unsatisfactory ones of victim or battlefield (Ibba 1991: 607).

Insofar as this accusation states that the MILITARY metaphor does not provide a correlate for an important component of the AIDS context, it is perfectly conect: the MILITARY metaphor cannot provide an acceptable framework for understanding the patient's role within the AIDS context. In my view, this does not suggest that the MILITARY metaphor is an intentionally misleading or otherwise pernicious metaphor, however. Instead, I believe this just means that the MILITARY metaphor is not a metaphor in terms of which the patient-role can properly be understood; one must look elsewhere to find an appropriate conceptual tool to structure and understand the patient's experience within the AIDS context. This is clearly what healthcare workers have done - they work with the keyword patient-centred focus and, in so-doing, make it clear that the patient - and not AIDS or HIV - is the central focus of AIDS care. Just as I said in connection with Accusation III, then, it should be remembered in the case of Accusation IV that the power of conceptual metaphor should not be overestimated.

Accusation V : The MILITARY metaphor may be ambiguously interpreted insofar as the identity of the enemy in the war is concerned. Ross (1989: 55) warns that with the MILITARY metaphor, "[w]e run the risk of destroying people, not a vinus." Sontag also cautions (1988: 11) that the 
MILITARY metaphor can contribute to the stigmatizing not only of an illness, but also of those who are infected with that illness.

As far as these criticisms apply to the abuse of the MILITARY metaphor outside the AIDS context, I do not dispute that the MILITARY metaphor has sometimes consciously been exploited in order to stigmatize AIDS sufferers. Within the medical context, however, manipulation of this nature via the MILITARY metaphor understandably does not feature: bealthcare staff have their patients' best interests at heart. What does sometimes occur within the medical context, though, is that healthcare staff and even their patients unintentionally abuse the MILITARY metaphor. Thus a patient, having heard thís formula bandied about in the media, may describe himself as harbouring ${ }^{7}$ the virus thereby seeming somewhat ludicrously to suggest that he is aiding and abetting the virus. Such a patient is guilty (if he is guilty at all) of linguistic ineptitude, rather than linguistic abuse. Once again, Accusation V therefore seems to be irrelevant within the AIDS context.

\section{CONCLUSION}

Having reached the conclusion of this paper, I hope I have gone some way to showing that the denigration the MILITARY metaphor has received at the hands of writers such as Sontag and Ross does not do justice to the metaphor as it is used within the AIDS context. Within this context, the MILITARY metaphor is not used primarily to frighten or to promote harmful fallacies. Instead, it is fruitfully and realistically employed by medical staff and counsellors alike to make something mysterious, alanning and overwhelming a little less so. 


\section{FOOTNOTES}

Note : All the linguistic data cited in this paper is drawn from a corpus of data which 1 accumulated during research for an article which was written in partial fulfilment of the requirements for the Masters degree in General Linguistics (University of Stellenbosch, 1995).

1. In keeping with the convention employed by Lakoff, Johnson, Tumer and Holland - and, I am sure, a great many others - I will indicate conventional metaphors by means of CAPITAL LETTERS.

Note : Ross refers to what I am designating the MILITARY metaphor as the WAR metaphor.

2. In this paper, I will refer to all people suffering from AIDS as AIDS patients. I have chosen this formulation for ease of reference, although it is not the formulation advocated by members of Body Positive - they prefer the longer people living with AIDS.

3. Because innocent and guilty form a complementary pair, the existence of innocent victims implicitly presupposes the existence of guilty victims.

4. The MEDICINE IS WAR metaphor originated as a result of modern technological society's characteristic hubris: in this day and age where life and the ability to control our environment as it suits us are regarded as a right, disease can no longer by viewed as a biological manifestation of a natural phenomenon; instead, it must be seen as an outrage which must be quelled at all costs.

5. Body Positive is a worldwide organization for people living with AIDS (this is their formulation; they reject the labels AIDS victims and AIDS sufferers). As its name suggests, Body Positive encourages its members to remain positive about their condition, particularly while they are seropositive or have not developed so-called fullblown AIDS Many of its members are involved in AIDS education campaigns or in caring for those who can no longer look after themselves.

6. $T-4, T-8, B, C D 4$ and $B 2 M$ are just some of the names immunologists use to refer to immune cells involved in AIDS. 
7. As Ross (1988: 44) points out, the word harbour is probably most closely associated with spies and criminals. One might, for example, speak of individuals harbouring fugitives. Such an action does, of course, constitute treason and is consequently a $\therefore$ i criminal (and in some countries even capital) offence. When one says that an AIDS patient is harbouring the HIV virus, one therefore also seems to be suggesting that this person is hiding the virus knowingly, willingly and with bad intentions. By extension, one could therefore also suggest that the AIDS patient is every bit as much an enemy as the HIV which he is concealing. 


\section{BIBLIOGRAPHY}

Bliesener, T. and J. Siegrist. 1981. Greasing the wheels; conflicts on the round and how they are managed. Journal of Pragmatics 5: 181 - 204.

Hodgkin, P. 1985. Medicine is war and other medical metaphors, British Medical Journal 291: $1820-1821$

Holland, D. 1982. All is metaphor: conventional methods in human thought and language. Reviews in Anthropology (Summer 1982): 287 - 297.

Ibba, M. 1991. Metaphors we are healed by: on the use of metaphors in medical language. In: Alatis, J.E. (ed.) Georgetown University Round Table on Language and Linguistics. Washington: Georgetown University Press.

Jemmot, J. 1985. Psychoneuroimmunology: the new frontier. American Behavioural Scientist 28(4): 497 - 509.

Kiecolt-Glaser, J. and R. Glaser. 1992. Psychoneuroinumunology: can psychological interventions modulate immunity: Journal of Counselling and Clinical Psychology $60(4): 569-575$.

Lakoff, G. and M. Johnson. 1980. Metaphors we live by. Chicago and London: University of Chicago Press.

Lakoff, G. and M. Johnson. 1981. Conceptual metaphor in everyday language. In Johnson, M. (ed.) 1981. Philosophical perspectives on metaphor. Minneapolis University of Minnesota Press: $286-325$.

Lapierre, D, 1991. Beyond Love. London: Arrow Books.

Máseide, P. 1981. Sincerity may frighten the patient: medical dilemmas in patient care. Journal of Pragmatics 5: 145 - 167.

Reich, W. 1989. Speaking of suffering: a moral account of compassion. Soundings 72(1) 83 - 108. 
Ross, J. 1988. Ethics and the language of AIDS. In: Pierce, C. and D. van de Veer (eds.). Ethics and public policy. New York: Wadsworth Press: $39-55$

Ross, J. 1989. The militarizatiion of disease: do we really want a war on AIDS? Soundings 72(1): $39-58$.

Sontag, S. 1977. Illness as metaphor. London: Allen Lane.

Sontage, S. 1988. AIDS and its metaphors. New York: Farrar, Strauss and Giroux. 